\title{
The measurement of multiple dimensions of subjective well-being in later life
}

Link to publication record in Manchester Research Explorer

\section{Citation for published version (APA):}

Vanhoutte, B., Bram, V., Field, J. (Ed.), Burke, R. J. (Ed.), \& Cooper, C. L. (Ed.) (2013). The measurement of multiple dimensions of subjective well-being in later life. In The SAGE handbook of Aging, Work and Society (pp. 493-513). Sage Publications Ltd.

\section{Published in:}

The SAGE handbook of Aging, Work and Society

\section{Citing this paper}

Please note that where the full-text provided on Manchester Research Explorer is the Author Accepted Manuscript or Proof version this may differ from the final Published version. If citing, it is advised that you check and use the publisher's definitive version.

\section{General rights}

Copyright and moral rights for the publications made accessible in the Research Explorer are retained by the authors and/or other copyright owners and it is a condition of accessing publications that users recognise and abide by the legal requirements associated with these rights.

\section{Takedown policy}

If you believe that this document breaches copyright please refer to the University of Manchester's Takedown Procedures [http://man.ac.uk/04Y6Bo] or contact uml.scholarlycommunications@manchester.ac.uk providing relevant details, so we can investigate your claim.

\section{OPEN ACCESS}




\title{
The measurement of multiple dimensions of subjective well-being in later life
}

\author{
Dr. Bram Vanhoutte \\ Centre for Census and Survey Research, School of Social Sciences, University of Manchester. \\ Bram.vanhoutte@manchester.ac.uk
}

\section{Introduction: Why measure well-being?}

In the last decades, well-being has received increasing attention from both social scientists and government officials. On an international level, the OECD has included subjective measures in its statistics since the declaration of Istanbul in 2007. Similarly the EU Commission and Eurostat have launched initiatives to capture subjective components of well-being. These developments on the international level have incited national and regional initiatives, among which the most influential are the 2009 French Commission on the Measurement of Economic Performance and Social Progress, headed by Joseph Stiglitz, Amartya Sen and Jean-Paul Fitoussi, and the more recent effort of the UK Office for National Statistics to Measure Well-Being (Beaumont, 2011) .

The fairly recent policy interest in measuring subjective well-being is based on a longer tradition of academic research into quality of life (Nussbaum \& Sen, 1993) and positive psychology (Seligman \& Csikszentmihalyi, 2000), aimed at extending the focus of research in the behavioural sciences from problematic behaviour to positive qualities, from repairing and healing to enhancing the ability of individuals to maintain a good life (Seligman \& Csikszentmihalyi, 2000). In an ageing society, it can be said that measuring subjective well-being and enhancing a good later life are even more important.

In this chapter an overview of the existing approaches to examine subjective well-being in later life is given. The focus is on subjective measures of well-being, but I acknowledge that different approaches such as objective lists of conditions from which well-being emerges (Nussbaum \& Sen, 1993) or preference satisfaction (Dolan \& Peasgood, 2008) also have their merits. Both theoretical background and methodological issues of the measures are addressed. An important division in measuring instruments is made on the basis of different philosophical backgrounds of what wellbeing actually entails (Ryan \& Deci, 2001). Is subjective well-being mainly about being happy, or are there other things than pleasure and pain, such as self-actualisation, that influence one's level of contentment? Both approaches to well-being, classified as respectively hedonic and eudaimonic well-being, are a first point of attention. A second point of interest is the structure of measurement instruments of well-being when applied to the English Longitudinal Study of Ageing (ELSA). Do the structural models mentioned in the literature, usually tested on either relatively small samples of university students or large scale population surveys, also fit people aged 50 or older in England? 


\section{Different approaches to measuring subjective well-being}

In everyday life subjective well-being (SWB) is probed for by the straightforward question "How are you?", but accurate and reliable assessment of well-being is at the base of a quite complex and substantial debate. Subjective well-being is often used in conjunction with physical health, and is commonly used as a concept for psychological health. Secondly, it is seen as the subjective counterpart of objective indicators for quality of life, and involves an individual judgement. A third point which defines subjective well-being is that, just like its counterparts madness and illness, it is at least partly a social construct. What wellbeing entails therefore depends not only on the psychological outlook one has on life, but equally on the position in society and the society one lives in. This makes any enquiry into the nature of well-being a meeting ground between philosophical theory and empirical measurement (Sumner, 1999).

\subsection{Hedonic well-being}

The hedonic view on well-being assumes that through maximizing pleasurable experiences, and minimizing suffering, the highest levels of well-being can be achieved. This emphasis on pleasure and stimulation entails not only bodily or physical pleasures, but allows any pursuit of goals or valued outcomes to lead to happiness. Both cognitive and affective aspects of well-being can be identified within this approach (Diener, 1984). A high level of well-being in the hedonic approach consists of a high life satisfaction, the presence of positive affect and the absence of negative affect (Diener, 1984). Well-being resides within the individual (Campbell, Converse, \& Rodgers, 1976), and therefore does not include reference to objective realities of life, such as health, income, social relations or functioning.

The affective aspect of hedonic well-being consists of moods and emotions, both positive and negative. Positive and negative affect each form a separate domain, and are not just opposites (Watson, Clark, \& Tellegen, 1988). Positive affect (PA) is a state wherein an individual feels enthusiastic, active and alert. High PA means high energy, full concentration and pleasurable engagement, while low PA encompasses sadness and lethargy. Negative affect generally captures subjective distress and unpleasurable mood states, such as anger, disgust, guilt, fear and nervousness. Low negative affect (NA) on the other hand encompasses calmness and serenity. Both positive and negative affect are usually measured by letting the respondent assess the prevalence of a number of emotional states in the last month (Watson et al., 1988). The affective approach to wellbeing can be traced back to the first enquiries on psychological well-being and quality of life (Bradburn, 1969).

The affective aspect of well-being brings measurement very close to assessing mental health. Therefore it is not surprising that depressive symptoms are sometimes used as a measure of NA (Demakakos, McMunn, \& Steptoe, 2010). Depression is traditionally assessed by the Centre for Epidemiological Studies Depression (CES-D) scale (Radloff, 1977), which has been shown to be accurate and valid among the older population as well as at younger ages (Lewinsohn, Seeley, Roberts, \& Allen, 1997). A second measure for mental health, the 12 item version of the General 
Health Questionnaire (GHQ) (Goldberg, 1988) can be seen in the light of affective measures of SWB as well. The GHQ-12 is a widely used screening tool for psychiatric disturbance, and has shown to have good psychometric properties and reliability for older people (Cheung, 2002).

In relation to later life, affective aspects of well-being have been studied quite intensively. On the level of measurement, it has been illustrated that the PANAS scale (Watson et al., 1988) has good psychometric and scale properties among the old, and yields information that is comparable to other age groups (Crawford \& Henry, 2004; Kercher, 1992; Kunzmann, Little, \& Smith, 2000). In regard to differences in mean levels of affect, it is an established fact that NA decreases over the lifespan, albeit the rate of decline is slower in old age, and may reverse in old-old age, while results for PA are not unequivocal (Charles, Reynolds, \& Gatz, 2001; Crawford \& Henry, 2004; Kunzmann, 2008; Kunzmann et al., 2000; Ready et al., 2011). Investigations into the facets of emotions, there is some evidence that although PA and NA are valid and separate factors, the structure of the interrelations among emotions in older adults differs from younger adults (Ready et al., 2011). Specifically sadness and depressive feelings seem to be more interrelated with anxiety. In connection to that, some studies report more somatic symptoms than emotional moods of depression by older adults (King \& Markus, 2000), leading to the challenged idea that depression manifests itself in a different way for older adults, a phenomenon called later life depression (Alexopoulos, 2005; Lebowitz et al., 1997). As depression is not a monolithic disease, but an emotional disorder accompanied by physiological symptoms, it is difficult to distinguish it from conditions in later life that trigger similar symptoms, such as chronic illness or cognitive impairment as the result of dementia or Alzheimer's disease (Lebowitz et al., 1997). In addressing this issue, it is helpful to make a distinction between major depression, which is less prevalent among the elderly (2\%), and minor depression (15\%), which is more common, and closely interrelated with stressful life events in later life and vascular risk factors (Beekman \& Deeg, 1995; Van den Berg et al., 2001). While the CES-D scale and GHQ are robust instruments to measure major depression in later life, they are less accurate in picking up minor depression (Papassotiropoulos, Heun, \& Maier, 1999; Watson \& Pignone, 2003).

The cognitive component of hedonic well-being, often referred to as life satisfaction, is a judgemental process in which individuals asses the quality of their life based on their own set of criteria (Pavot \& Diener, 1993). As such, it differs from domain specific evaluations of satisfaction (Campbell, Converse, \& Rodgers, 1976) in that an idiosyncratic set of standards is taken into account, which allows comparing satisfaction with life over groups of people with different aspirations in life. The Satisfaction With Life Scale (SWLS) (Diener, Emmons, Larsen, \& Griffin, 1985; Pavot \& Diener, 1993) consists of 5 items to be rated on a response scale ranging from 1 (strongly disagree) to 7 (strongly agree), inviting respondents to make a global evaluation of their life. It was also explicitly tested on older respondents (Diener et al., 1985). From a methodological perspective, it is surprising that all the items are worded in a positive way, because this way the scale could suffer from extreme response and acquiescence bias. Often at least one item is worded in a negative sense, to avoid respondents answering without really thinking about the question asked.

Perceptions about the self and one's own life tend to be too positive and optimistic (Kahneman \& Thaler, 2006; Taylor \& Brown, 1988), so that hedonic well-being ultimately depends on how high or low one sets his goals. This judgemental relativity is seen as a major problem in assessing the validity across the population for hedonic cognitive measures, as even a slave can be happy. Similarly, adaptation plays a main role in the cognitive process of accepting the circumstances as they are and moving to a normal level of well-being (see further). A second severe criticism on well-being as 
maximizing pleasure, is that negative events have an important role in providing insight about oneself, or growing as a person (Ryff \& Singer, 1998). Positive psychology itself is deeply rooted in investigating which type of persons are resilient to negative conditions (Seligman \& Csikszentmihalyi, 2000).

Figure 1 about here-

\subsection{Eudaimonic well-being}

A second, and in practice largely complementary (Waterman, 1993), approach starts from a different concept of well-being. A good life is not just about pleasure and happiness, but involves developing one-self and realizing one's potential (Ryff \& Keyes, 1995). Eudaimonic well-being reflects positive functioning and personal expressiveness. Positive functioning, or psychological well-being, reflects the need for self-actualisation in Maslow's (1968) need hierarchy. Similarly, positive functioning can be seen from the perspective of developmental psychology, as personality changes articulate wellbeing as trajectories of continued growth across the life cycle (Erikson, 1959).

As the concept of positive functioning is rooted in different approaches, several different measurement instruments can be found. Ryan and Deci (2000) conceptualize it in their selfdetermination theory and see autonomy, competence and relatedness as three basic necessities for personal growth, integrity and well-being. By looking at six distinct aspects of actualisation (autonomy, personal growth, self-acceptance, life purpose, mastery and positive relatedness), Ryff \& Keyes (1995) measure psychological well-being, which they see separate from subjective well-being.

In the framework of studies on later life, a measure specifically targeted at older populations has been developed (Hyde, Wiggins, Higgs, \& Blane, 2003). Four constructs, namely Control, Autonomy, Self-realization and Pleasure (CASP) together can be seen as an accurate measure of positive functioning, and subjective quality of life in later life. An explicit aim of this measure from it's conception was to distinguish quality of life from it's drivers, such as health (Hyde et al., 2003). Therefore it is quite surprising to see explicit references to the respondents' age and health on the item level, in items such as "My age prevents me from doing the things I would like to" and "My health stops me from doing the things I want to do". Theoretically this is unsound because it contaminates the measure with aspects of health status. From a methodological point of view, a confirmatory factor analysis by the developers of the measure has equally shown that the error term of the item referring to health correlates with some other items in the scale, and that the scale shows better properties in a reduced form with 12 items (Wiggins, Netuveli, Hyde, Higgs, \& Blane, 2008). A second point of importance concerns the domain of Pleasure, which could be seen more as a hedonic than a eudaimonic form of well-being. When looking at different measures of well-being at the same time, this should be kept in mind.

Comparing the dimensionality of different conceptualisations of eudaimonic well-being it becomes clear that in large lines they rely on very similar concepts and sub-dimensions (see Table 1). All three approaches depart from the idea that human flourishing depends on the satisfaction of certain 
psychological needs. Autonomy is a need that is present explicitly in psychological well-being (PWB), self determination theory (SDT) and CASP. Both control in CASP, and environmental mastery in PWB can be seen as a closely related concept, relating to autonomy. The second key aspect of eudaimonic well-being is developing one-self, and is captured as personal growth in PWB, as competence in SDT and self-realisation in CASP. The largest difference between the three approaches is that both PWB and SDT do not see pleasure, or any other aspect of Diener's hedonic concepts as an explicit psychological need (Diener, Sapyta, \& Suh, 1998; Ryff \& Singer, 1998), while CASP does. While Ryff \& Singer (1998) downplay the importance of hedonic well-being altogether, Ryan \& Deci (2001) see it as a consequence of the fulfilment of needs, that goes hand in hand with eudaimonic well-being. Secondly, relatedness, or having warm and positive social relations, is seen as an essential need for psychological wellbeing, while it is not explicitly defined in the CASP scale.

----Table 1 about here

\subsection{Retrospective, Experienced and Reconstructed Well-being}

A second form of measurement diversity reflects theoretical and methodological considerations on the nature of changes in well-being. Is well-being a relatively stable stock product, affected little by fluctuations over time and life-events, or can it better be characterized as a flow, volatile and changeable? In later life, the evolution of well-being over time is specifically interesting, as old age is often characterized as a period in life where health risks and social losses occur within a short timespan.

One way to look at well-being is to see it as experienced utility in the classical economical sense. Probing for someone's level of well-being as a stock, by using self reporting in surveys, can be prone to errors because of effects of social desirability, judgement and memory, which have been illustrated extensively in the case of hedonic well-being (Kahneman \& Thaler, 2006). Nevertheless, both hedonic and eudaimonic self-reported well-being have shown to be grounded in reality, as they are closely associated to the attribution of positive personality traits by both acquaintances and clinicians, and cheerful, socially skilled behaviour (Kahneman \& Krueger, 2006; Nave, Sherman, \& Funder, 2008).

To emphasize the flow of hedonic well-being, alternative methods of collecting information have been set up. One influential but time-consuming approach is experience sampling (Csikszentmihalyi, 1990), where people report their moods and emotions on the spot in everyday life, by describing the activity they are doing and the pleasure achieved from it when a timer beeps, which happens several times during a day. In a recent effort to make this information easier to acquire, the day reconstruction method, where the respondent reconstructs his previous day episode by episode and then assigns moods to each period, has shown to be a reliable equivalent (Kahneman, Krueger, Schkade, Schwarz, \& Stone, 2004).

A last influential approach to changes in well-being focuses on the impact of positive and negative effects of life events and changes in conditions. The main argument is that there is a form of adaptation, or treadmill effect, meaning that well-being levels adapt to both positive and negative events and emotions, so that there is no actual evolution in the long term (Brickman \& Campbell, 
1971; Diener, Lucas, \& Scollon, 2006). Although there initially was substantive evidence for the treadmill effect when looking at hedonic measures of well-being (Brickman, Coates, \& Janoff-Bulman, 1978), some substantial revisions to the treadmill argument have been suggested (Diener et al., 2006). A first domain of concern is set point theory, or the idea that there is a fixed level of wellbeing that one departs or returns from when experiencing an event. These points are multidimensional, meaning that they can differ for affective and cognitive aspects of well-being. Set point also are not neutral, but instead tend to be positive (Diener \& Diener, 1996), and vary considerably among individuals, due to inborn personality based influences (Diener, Suh, \& Lucas, 1999). Secondly, while the treadmill argument implies that people eventually adapt the both good and bad circumstances, it has been illustrated that change does happen on the long term, for example when faced with unemployment (Lucas, Clark, Georgellis, \& Diener, 2004), or loss of a partner (Lucas, Clark, Georgellis, \& Diener, 2003). The extent to which adaptation occurs is heavily dependent on the individual as well, and coping and personality characteristics seem to play an important role. It has to be kept in mind that the bulk of the research on this topic has examined hedonic well-being. Nonetheless, also when it comes to eudaimonic well-being processes of adaptation can be thought of, especially when looking at self-realisation (Waterman, 2007). The experience of flow (Csikszentmihalyi, 1990), when the challenge posed and the skill of an individual are balanced, could become quite rare as a person is becoming more experienced and hence more skilled, leading to an eudaimonic treadmill. Waterman (2007) argues that the opposite is actually the case, since eudaimonic well-being is the result of striving more than the actual outcome, and new fields for self-realisation are in practice endless.

In this analysis we will limit ourselves to the traditional retrospective, self-reported, measurements of hedonic and eudaimonic well-being, but it is clear that alternative measures are possible and available.

\section{Assessing measurement}

It is beyond the scope of this paper to examine all possible aspects of the measurement of wellbeing. In this analysis we limit ourselves to a more conceptual question on the nature of well-being: Can well-being be seen as a single dimension or not? To what extent do different scales reflect different aspects of well-being? In a first step the ideal structure for several aspects of subjective well-being, reflected in different scales is investigated. While some scales were specifically designed for an older population (CASP), others are scales (SWLS, CES-D, GHQ) usually applied to a general population sample. Therefore it is important to look at the structure of these scales specifically for an older population, and to investigate if they function in the same way as they do in the general population. In a second step, a second-order model of well-being is constructed, to see how the different sub-dimensions relate to each other. Can we really distinguish two main dimensions, a eudaimonic and a hedonic form of well-being, or is a different conceptual framework more suited when looking at well-being in later life? A last important note is that while focuses on problems associated with measurement, it does not insinuate that analyses based on 'bad' versions of a scale are flawed. Measurement models are very useful in testing the latent structure behind a scale, but usually using a refined scale does not alter substantive conclusions based on robust analysis.

\subsection{Data and methods}


These questions will be investigated using the self-completion part of the first three waves (collected in respectively 2002, 2004 and 2006) of ELSA (Marmot et al., 2011)'. Different waves are used, because although not all instruments are present in the first or second wave, they have larger sample sizes (respectively 10253 and 8780 ) and as such allow for greater variability in the data. The third wave (using both core sample members and the refreshment sample, in total 8598 respondents) is used to asses the interrelations between all available scales. The exact item wording and answering categories used can be found in the appendix.

The structure of the scales is often examined using factor analysis. Two main forms of factor analysis can be distinguished: exploratory factor analysis (EFA) and confirmatory factor analysis (CFA). EFA is more data-driven, and is often used in scale development, when there is little underlying theory on how items should load on a factor, or how many factors are present. CFA is used to test and confirm theoretical hypotheses on scale structure, as is the case in this chapter.

Examining scale structure consists of making the best configuration of items and factors based on substantive theory. A good scale structure in the first place consists of high factor loadings across the items that define it. A second, connected issue is the number of factors, or sub dimensions that exist in a scale. In EFA, the data provides the number of dimensions asked and it's up to the researcher to determine the criterion for cut-off. The extensive use of EFA has been criticized, as it assumes that variables are measured perfectly, without any form of measurement error, so that all observed variance is true score variance (Brown, 2006). Secondly, a false number of factors can surface if method effects are not taken into account (Brown, 2003; Chen, Rendina-gobioff, \& Dedrick, 2010; DiStefano \& Motl, 2009; Hankins, 2008; Van de Velde, Bracke, Levecque, \& Meuleman, 2010; Wood, Taylor, \& Joseph, 2010). One possible method effect is that items posed in a negative manner can provoke different answers of a respondent, not due to the substantive matter but rather to the fact that the item is worded negatively (Marsh, 1996). Asking someone 'how often are you unhappy' is not simply the inverse of 'how often are you happy'. To account for this with CFA, one can either specify a separate and uncorrelated method factor, on which negatively worded items load, or allow error correlations between negatively worded items in the scales.

Usually maximum likelihood estimation (MLE) is used to estimate CFA models, but although this method is more precise in parameter estimation, it's limited to estimating two or three factors. A different estimator, weighted least squares means and variances adjusted (WLSMV), is computationally more efficient and gives equally reliable estimates as MLE (Beauducel \& Herzberg, 2006). A positive aspect of this method is that since it does not assume normality of the distribution over the different answering categories, it can handle categorical or binary data. A drawback is that the chi-square based statistics cannot be directly compared between nested models, as is the case with MLE.

To determine which model fits better, a number of test statistics are available. The tests most widely used are the Root Mean Square Error of Approximation (RMSEA) (lower than .8 for decent fit and lower than .06 for good fit), the Comparative Fit Index (CFI) (higher than .95 for good fit) and Tucker Lewis Index (TLI) (higher than .95 for good fit) (Hu \& Bentler, 1999). Similarly the size of factor loadings will be taken into account, because the use as a sum scale requires all items to load equally good (more than .60) on the latent constructs. A low factor loading means that in practice the item does not contribute a great deal to the latent measure. 


\subsection{Identifying factor structures}

\subsubsection{CASP}

The CASP scale, a measure of quality of life in later life, in its original form has 19 items, but revised forms of 12 items (Wiggins et al., 2008) and 15 items (Vanhoutte, 2012) have been proposed for use. CASP is present in the self-completion questionnaire in its 19 item form in waves 1 to 5 of ELSA. Since often the individual items are not mentioned when the scale is used, and the psychometric tests on the original scale are referred to, it is relevant to investigate the structure of the latent concept in all versions of the scale. In the original study that tested the qualities of the CASP scale, a four dimensional structure was proposed for the 19 item scale, and a three dimensional structure was proposed for both the 12 and 15 item version (Vanhoutte, 2012; Wiggins et al., 2008).

\section{Figures A-E}

In our analysis the dimensionality of the CASP scale is investigated, next to the usefulness of accounting for negative item wording. Understanding the differences between the structure of the models is key to grasping how confirmatory factor analysis is used to test theoretical models, therefore a schematic representation of the models is shown above (figures 2-6). The 19 item CASPscale is used to illustrate the possible model configurations. The baseline model (figure 2) assumes all items load onto the same factor. Each item is associated with an item-specific error term, which represents the variation that is not accounted for by the latent factor, in this case the CASP scale. To account for the possible measurement bias introduced by negative item wording, two possible specifications are used interchangeably in the literature. A first option is to allow correlations between the error terms of the items that are phrased negatively (figure 3). A second, more restricting option is to specify a latent 'method' factor onto which these items load, next to their loading onto the substantive factor (figure 4). If less than three items are phrased negatively, only error correlations are possible since a factor needs at least three items to be identified. As the dimensionality of CASP is also a point of interest, different models are specified to see which solution gives us the best factor model. A division between eudaimonic and hedonic aspects of wellbeing can be expected following the literature, so a two factor solution, isolating pleasure from control, autonomy, and self-actualisation, should also be tested (figure 5). The best fitting model for CASP in other studies (Vanhoutte, 2012; Wiggins et al., 2008), distinguishing three dimensions, is also specified (figure 6). Multidimensional models can equally be specified with a method factor or error correlations.

Table 2 illustrates the results for these different configurations of the 15 item version of the CASP scale

-Table 2 about here-

In the best fitting solution, with three factors, each dimension is measured by 5 items, and error correlations are allowed between negatively phrased items. It is also clear that the negative item wording has an effect on the model, and as such should be taken into account.

\subsubsection{CES-D}


The original CES-D scale (Radloff, 1977) comprises 20 items, but shorter versions are frequently used and have shown not to lose a lot of information (Kohout, Berkman, Evans, \& Cornoni-Huntley, 1993). In ELSA an 8 item version is used. When looking at the CES-D scale in its extended form with EFA, four sub-dimensions surface: positive affect, depressed affect, somatic complaints and interpersonal problems (Kohout et al., 1993; Radloff, 1977; Ross \& Mirowsky, 1984). In the 8 item version only two subscales surface, one that captures mood symptoms and one that refers to somatic aspects of depression (Van de Velde et al., 2010; Wallace et al., 2000). The scale can be seen as a single scale, since internal consistency is high, and correlations between the sub dimensions are higher than .90 in the general population(Van de Velde et al., 2010). In this analysis we will look at the two factor solution, since theoretically depression in later life is explicitly linked to its somatic component. Testing the scale in a CFA framework, it has also been established that the CES-D scale represents a continuum rather than forming separate factors for positively and negatively worded items, if correlations between negatively worded items are allowed (Wood et al., 2010).

-------Table 3 about here

All fit statistics, both for one or two factors, are acceptable (see Table 3). It is clear that allowing error correlations between negatively worded items significantly improves the models. The two factor model has a better fit, and there is a correlation of .82 between both factors, which is still high, but substantially lower than the .90 reported in the general population. The data clearly favour the most complex model, with two factors and error correlations between the negatively worded items, but even a simple one factor model has an acceptable fit, illustrating the robust reliability of the shortened CES-D scale.

\subsubsection{General health Questionnaire (GHQ)}

The GHQ is a 12 item scale, intended as a general screening instrument for psychiatric morbidity (Goldberg \& Williams, 1988). Most researchers examining the factor structure have focused on the number of sub dimensions. While a large part of the scientific work has been highlighting the plausibility of a two or three factor structure (anxiety, social dysfunction and loss of confidence) instead of the original one factor (Graetz, 1991; Shevlin \& Adamson, 2005), recently the inclusion of method effects of negative wording has shown this multidimensionality to be a measurement artefact (Hankins, 2008). The two dimensional structure groups positive and negative items in separate dimensions, just like the three dimensional model (anxiety, social dysfunction and loss of confidence)(Graetz, 1991).

Table 4 about here-

Our test on a representative sample of community dwelling people aged 50 or older seems to confirm these findings, showing a robust one factor solution (see Table 4). Since there is a significant difference in fit between the specifications with error correlations and the method factor, allowing the error correlations might be masking substantial aspects of the scale. Therefore the three dimensional model is preferred to allow for greater conceptual nuance.

\subsubsection{Satisfaction with life scale (SWLS)}

The satisfaction with life scale (Diener et al., 1985) is commonly seen as a one dimensional scale for global life satisfaction, comprising 5 items (Pavot \& Diener, 1993), but sometimes even only a single 
item is used (Morrison, Tay, \& Diener, 2011). Some find a two factor structure for the SWLS (McDonald, 1999; Wu \& Yao, 2006), with the last two items of the scale, which refer more to past experiences, having a different importance for the total score both in later life compared to younger people, and in different cultures compared to the US, where the scale has been most extensively tested (Hultell \& Petter Gustavsson, 2008; Oishi, 2006; Pons, Atienza, Balaguer, \& García-Merita, 2000). These two factors are very closely related in most studies (correlation around .90). Since all items are worded in the same sense, a method factor is not necessary. Since the scale was only included from ELSA wave 2 onwards, we tested the models on wave 2.

-----Table 5 about here-

Both the one factor and two factor model do not seem to fit very well according to the RMSEA, but have a very good fit according to the CFI. The two factor model fits marginally better, but the correlation between both factors is very high (.938). It is a quite surprising finding that one of the most used scales to measure subjective well-being does not fit particularly well for older respondents in England. Modification indices indicate that being satisfied with life (item c) is more closely related to evaluating one's life as ideal (item a), and less to perceiving one's life conditions as ideal. We allow this correlation, and keep in mind that conditions seem to be less important for life satisfaction among the elderly in the UK.

\subsection{Well-being measures combined: A second order measure of well-being}

Now that we have an indication on the structure of separate aspects of well-being, it can be investigated to what extent these different aspects coincide. From the theory a number of specific hypotheses on the structure of wellbeing can be deducted. The most influential approach in wellbeing research, hedonic well-being, based on the work of Diener, assumes two components, an affective part, captured in our measurements by the CES-D and GHQ scales and a cognitive part, in our available data the SWLS (Diener, 1984; Diener et al., 1999; Pavot \& Diener, 1993). An alternative approach states that wellbeing results not from happy mood or a good evaluation of one's life, but through attainment of life goals. This eudaimonic approach does not directly address it's relation with hedonic measures, but sees itself as a separate and conceptually different approach to measuring wellbeing. This raises the question if and to what extent both approaches are different from one another.

--------Table 6 about here-------

Two aspects of our available data complicate this undertaking. Firstly, not all scales are available in each wave of ELSA (Table 6). Therefore we will present the findings of the analysis on the most complete set of measures, in wave 3, in the text." Secondly, each scale allows a different way of answering an item. The CES-D items are binary in nature, while both CASP and GHQ provide 5 response categories and the SWLS 7. Although the CASP and GHQ items have the same number of answering possibilities, their meaning differs as in CASP the frequency of something happening is asked for, while in GHQ the respondent is asked to compare the something with their 'usual' behaviour. This means that the highest correlations between sub-dimensions will logically occur within the same scale. It is nonetheless useful to look at the correlations between the sub- 
dimensions to investigate which aspects of well-being are less related. Correlations lower than .60 are considered weak, while correlations higher than .75 are considered strong.

------Table 7 about here-

The 10 factor model, specifying all subscales of all available measures of well-being, and error correlations between negatively worded items within each scale, has a good fit (Model 1 in Table 9). A first step in examining the interrelations of aspects of wellbeing is to examine the correlations in detail (Table 7). As expected, the highest correlations can be observed between subscales derived from a similar instrument. More relevant for the topic of this paper, is that a number of concepts only are weakly related to each other. Satisfaction with life in general can be seen as only weakly related to most aspects of mental health, which is indicated by the moderate correlations with most subscales of the GHQ and CES-D. On the other hand satisfaction with life, especially in the present, is strongly related to self-actualisation. Anxiety is closely related to symptoms of a depressive mood, but less to self-actualisation and pleasure. Loss of confidence seems closely associated with low control and autonomy. Somatic symptoms of depression are especially weakly related to satisfaction with past life, and only moderately with satisfaction with life in the present, or pleasure. In general depressed mood is slightly closer related to satisfaction with life and general mental health compared to somatic symptoms. Surprisingly the pleasure domain of CASP is not more strongly related to the hedonic measures in comparison with the domains control and autonomy and selfrealisation. This could indicate that for most respondents, enjoyment is something else than mere satisfaction. Similarly, no measure of positive affect is available in the current ELSA dataset, so it could well be that pleasure is not that closely related to negative affect and satisfaction with life, but more with positive affect. iii $A$ second explanation is that the frequency of enjoyment asked for in CASP is more related to eudaimonic aspects of well-being than satisfaction with current or past life. A last explanation is that eudemonia, or fulfilling one's psychological needs, is enjoyable and as such should always be seen as partly hedonic.

In a next step a number of theoretically grounded second order factor models (Table 8) are tested. This allows to draw conclusions on the most adequate conceptual model to represent subjective well-being in later life. A second order model essentially adds a latent factor measured by latent factors on top of the model. Theoretically this investigates to what extent the factors on the first level can be seen as representing a common part, or relate to a more abstract concept. What is specifically relevant for this chapter, is the configuration and dimensionality of the second order model. Is well-being in later life best captured by a single second order factor, where all subdimensions refer to the same latent concept, as in model 2? Or is a split between eudaimonic and hedonic well-being (model 3) more accommodating for our data? A second two dimensional structure could also be distilled from the literature, in the sense that eudaimonia is a part of hedonic cognitive well-being (model 4). A three factor latent structure, which distinguishes a hedonic affective, hedonic cognitive and eudaimonic component of well-being, could be seen as a compromise between these twodimensional models, and therefore also between hedonic and eudaimonic conceptions of well-being (model 5). A last possibility is that there is no real second order structure except the different scales used (model 6).

----Table 8 about here---

----Table 9 about here--- 
An overview of the model fit of these different second order models is given in table 9. Specifying a single second order factor (Model 2) means reducing all these aspects of well-being to a single dimension. Although this model has an acceptable fit in terms of RMSEA, this seems less the case for the other fit indices. This means that a single well-being concept is defendable, but does not fully grasp the complexity of the subject at hand. Distinguishing hedonic from eudaimonic well-being (Model 3), does not greatly improve the fit. The division between hedonic and eudaimonic measures seems less substantial than expected. It has to be kept in mind that pleasure is seen as a eudaimonic measure in this context. ${ }^{\text {iv }}$ Distinguishing affective from cognitive aspects of wellbeing (Model 4) on the other hand, has a substantial impact on the model fit, since this model approaches very good fit. The compromise between both two dimensional approaches (Model 5), specifying a dimension of hedonic cognitive, hedonic affective and eudaimonic wellbeing, fits our data very good, and adds conceptual nuance to subjective well-being. An extra factor for the two measurements of affective well-being (Model 6) does not really improve our model fit, so that we can confidently assume a three dimensional nature of wellbeing.

\section{Conclusions}

This paper investigates the empirical measurement of well-being in later life, by examining a number of commonly used scales and looking at their interrelations. This examination is framed in the discussion on the difference between hedonic and eudaimonic well-being. The dominant approach, hedonic well-being, assumes that well-being emanates from pleasure and the avoidance of painful experiences, however these are defined by the individual. Measuring wellbeing in this framework tries to capture moods and emotions on one hand, in the form of positive and negative affect, and cognitive evaluations of one's life on the other hand (Diener, 1984). Eudaimonic well-being is not such a unified approach as hedonic well-being, and consists of several multidimensional approaches (Hyde et al., 2003; Ryan \& Deci, 2000; Ryff \& Keyes, 1995). What they have in common is that they assume well-being emerges as a result of the satisfaction of universal human psychological needs. While Ryan \& Deci (2001) and Hyde et al. (2003) assume pleasure, or hedonic well-being, is one of those needs, Ryff \& Keyes (1998) state that at best there is a weak relation between need fulfilment and pleasure.

To what extent do indicators of these different aspects of well-being, commonly developed by testing on either relatively small groups of students or in population wide large scale surveys, replicate their structure among adults aged 50 or older in England? Both instruments aimed at capturing negative affect, CES-D and GHQ, performed most in line with their expectations. While considering CES-D as a one dimensional instrument screening for depression is acceptable, a more fine grained approach to depression clearly distinguishes somatic aspects from emotional ones. The GHQ measure in a similar vein is acceptable as a one dimensional construct, but allows more nuance when looking at anxiety, social and confidence aspects of mental health separately. Satisfaction with life, the most commonly used measure for well-being, seems to perform relatively poorly. Not only can a distinction between satisfaction with the past or present be made, which was already noted by other researchers (Hultell \& Petter Gustavsson, 2008; Oishi, 2006), in our sample satisfaction, more precisely seeing one's life as ideal, was less related with how one perceives his life conditions. The CASP scale was used in a revised 15 item version, and a balanced three dimensional structure, 
consisting of control and autonomy, self-realisation and pleasure, was found to be most accurate to measure eudaimonic aspects of wellbeing.

The relations between these different facets of well-being were largely in line with our expectations. Present satisfaction with life was slightly closer related to measures of negative affect, control and autonomy and self-realisation than satisfaction with the past life. Both present and past satisfaction were more related to aspects of human flourishing than to mental health and depression. Anxiety, social dysfunction, pleasure and both dimensions of satisfaction were more related to emotional symptoms of depression than somatic ones, while the associations were about the same for control and self-realisation. Surprisingly pleasure was not significantly closer related to both affective and evaluative aspects of hedonic well-being compared with other dimensions of the CASP scale. Looking at the second order structure of the scales, it is clear that the difference between hedonic and eudaimonic well-being had been exaggerated in the literature, and is smaller than the difference between affective and cognitive aspects of well-being. If a multidimensional concept of wellbeing is used, a threefold structure, distinguishing cognitive, affective and eudaimonic well-being is most informative.

What would help us answer the questions posed in this analysis better, or in other words what are the suggestions for further research? First of all, access and inclusion to more measures of wellbeing, such as positive affect and perhaps loneliness could broaden our understanding of how eudaimonic well-being relates to cognitive and affective aspects. In the case of loneliness this creates the question to which extent it should be seen as an aspect of well-being, and hence a basic psychological need, instead of a possible cause of low well-being, and hence a driver. Secondly, substantial analysis using multiple dimensions of subjective well-being can highlight how the mechanisms producing different forms of well-being differ. Up until now, most attention has been focused on cognitive measures of well-being, and as this chapter illustrated, this might not be the most reliable measure. A last suggestion in a similar vein, is to strengthen the theoretical work on how eudaimonic, affective and cognitive well-being are interrelated. While up until now most research efforts suing both hedonic and eudaimonic aspects of well-being are rather partisan in nature, and try to contrast and compare the relative merits of each approach, the real way forward lies in capitalising on the inherent value of both approaches. 


\section{Bibliography}

Alexopoulos, G. S. (2005). Depression in the elderly. Lancet, 365(9475), 1961-70. doi:10.1016/S0140-6736(05)66665-2

Beauducel, A., \& Herzberg, P. Y. (2006). Structural Equation Modeling??: A On the Performance of Maximum Likelihood Versus Means and Variance Adjusted Weighted Least Squares Estimation in CFA. Structural Equation Modeling, 13(2), 186-203.

Beaumont, J. (2011). Measuring National Well-being - Discussion paper on domains and measures. London.

Beekman, a T., \& Deeg, D. J. (1995). Major and minor depression in later life: a study of prevalence and risk factors. Journal of Affective Di, 36, 65-75. doi:10.1111/j.1752-0606.2011.00243.x

Bradburn, N. M. (1969). The structure of Psychological Well-being. Chicago: Aldine .

Brickman, P., \& Campbell, D. T. (1971). Hedonic relativism and planning the good society. In M. H. Appley (Ed.), Adaptation Level Theory A Symposium (pp. 287-302). Academic Press.

Brickman, P., Coates, D., \& Janoff-Bulman, R. (1978). Lottery winners and accident victims: is happiness relative? Journal of personality and social psychology, 36(8), 917-27.

Brown, T. A. (2003). Confirmatory factor analysis of the Penn State Worry Questionnaire: Multiple factors or method effects? Behaviour Research and Therapy, 41(12), 1411-1426. doi:10.1016/S0005-7967(03)00059-7

Brown, T. A. (2006). Confirmatory factor analysis for applied research. New York: The Guilford Press.

Campbell, A., Converse, P. E., \& Rodgers, W. L. (1976). The Quality of American Life: Perceptions, Evaluations, and Satisfactions. (p. 583). New York: Russell Sage Foundation.

Charles, S. T., Reynolds, C. A., \& Gatz, M. (2001). Age-related differences and change in positive and negative affect over 23 years. Journal of Personality and Social Psychology, 80(1), 136.

Chen, Y., Rendina-gobioff, G., \& Dedrick, R. F. (2010). Factorial Invariance of a Chinese Self-Esteem Scale for Third and Sixth Grade Students?]: Evaluating Method Effects Associated with Positively and Negatively Worded Items. International journal of educational and psychological assessment, 6(December), 21-35.

Cheung, Y. B. (2002). A confirmatory factor analysis of the 12-item General Health Questionnaire among older people. International journal of geriatric psychiatry, 17(8), 739-44. doi:10.1002/gps.693

Crawford, J. R., \& Henry, J. D. (2004). The positive and negative affect schedule (PANAS): construct validity, measurement properties and normative data in a large non-clinical sample. The British journal of clinical psychology / the British Psychological Society, 43(Pt 3), 245-65. doi:10.1348/0144665031752934 
Csikszentmihalyi, M. (1990). Flow: The Psychology of Optimal Experience. (H. Collins, Ed.)Annals of Physics (Vol. 54, p. 303). Harper \& Row.

Demakakos, P., McMunn, A., \& Steptoe, A. (2010). Well-being in older age: a multidimensional perspective . In J. Banks, C. Lessof, J. Nazroo, N. Rogers, M. Stafford, \& A. Steptoe (Eds.), Financial Circumstances, Health and Well-being of the Older Population in England. The 2008 English Longitudinal Study of Ageing. (pp. 115-177). London: Institute for fiscal studies.

DiStefano, C., \& Motl, R. W. (2009). Self-Esteem and Method Effects Associated With Negatively Worded Items: Investigating Factorial Invariance by Sex. Structural Equation Modeling: A Multidisciplinary Journal, 16(1), 134-146. doi:10.1080/10705510802565403

Diener, E. (1984). Subjective well-being. Psychological Bulletin, 95(3), 542-575.

Diener, E., \& Diener, C. (1996). Most people are happy. Psychological science, 7(3), 181-185.

Diener, E., Emmons, R., Larsen, R. J., \& Griffin, S. (1985). Satisfaction with life scale. Journal of personality assessment, $49(1), 71-75$.

Diener, E., Lucas, R. E., \& Scollon, C. N. (2006). Beyond the hedonic treadmill: revising the adaptation theory of well-being. The American psychologist, 61(4), 305-14. doi:10.1037/0003066X.61.4.305

Diener, E., Sapyta, J. J., \& Suh, E. (1998). Subjective Well-Being Is Essential to Well-Being. Psychological Inquiry, 9(1), 33-37.

Diener, E., Suh, E., \& Lucas, R. E. (1999). Subjective well-being: Three decades of progress. Psychological bulletin, 125(2), 276-302.

Dolan, P., \& Peasgood, T. (2008). Measuring Well-Being for Public Policy??: Preferences or Experiences?? Journal of Legal Studies, 37(2), 5-31.

Erikson, E. (1959). Identity and the life cycle. Psychological Issues, 1(1), 18-164.

Goldberg, D. P. (1988). A User's Guide to the GHQ. Windsor.

Goldberg, D. P., \& Williams, P. (1988). A user's guide to the General Health Questionnaire. Basingstoke.

Graetz, B. (1991). Psychiatric Epidemiology Multidimensional properties of the General Health Questionnaire *, 132-138.

Hankins, M. (2008). The reliability of the twelve-item general health questionnaire (GHQ-12) under realistic assumptions. BMC public health, 8, 355. doi:10.1186/1471-2458-8-355

Hu, L., \& Bentler, P. M. (1999). Cutoff criteria for fit indexes in covariance structure analysis: Conventional criteria versus new alternatives. Structural Equation Modeling: A, 6(1), 1-55.

Hultell, D., \& Petter Gustavsson, J. (2008). A psychometric evaluation of the Satisfaction with Life Scale in a Swedish nationwide sample of university students. Personality and Individual Differences, 44(5), 1070-1079. doi:10.1016/j.paid.2007.10.030 
Hyde, M., Wiggins, R. D., Higgs, P., \& Blane, D. (2003). A measure of quality of life in early old age: the theory, development and properties of a needs satisfaction model (CASP-19). Aging \& mental health, 7(3), 186-94. doi:10.1080/1360786031000101157

Kahneman, D., \& Krueger, A. B. (2006). Developments in the measurement of subjective well-being. Journal of economic perspectives, 20(1), 3-24.

Kahneman, D., Krueger, A. B., Schkade, D. A., Schwarz, N., \& Stone, A. A. (2004). A survey method for characterizing daily life experience: the day reconstruction method. (F. A. Huppert, B. Kaverne, \& N. Baylis, Eds.)Science, 306(5702), 1776-80. doi:10.1126/science.1103572

Kahneman, D., \& Thaler, R. H. (2006). Utility Maximization and Experienced Utility. Journal of economic perspectives, 20(1), 221-234.

Kercher, K. (1992). Assessing Subjective Well-Being in the Old-Old: The PANAS as a Measure of Orthogonal Dimensions of Positive and Negative Affect. Research on Aging, 14(2), 131-168. doi:10.1177/0164027592142001

King, D. A., \& Markus, H. E. (2000). Mood disorders in older adults. In S. K. Whitbourne (Ed.), Psychopathology in Later Adulthood (pp. 141-172). New York: Wiley.

Kohout, F. J., Berkman, L. F., Evans, D. a., \& Cornoni-Huntley, J. (1993). Two Shorter Forms of the CES-D Depression Symptoms Index. Journal of Aging and Health, 5(2), 179-193. doi:10.1177/089826439300500202

Kunzmann, U. (2008). Differential age trajectories of positive and negative affect: further evidence from the Berlin Aging Study. The journals of gerontology. Series B, Psychological sciences and social sciences, 63(5), P261-70.

Kunzmann, U., Little, T. D., \& Smith, J. (2000). Is age-related stability of subjective well-being a paradox? Cross-sectional and longitudional evidence from the Berlin Aging Study. Psychology and Aging, 15(3), 511-526. doi:10.1037//0882-7974.15.3.511

Lebowitz, B. D., Pearson, J. L., Schneider, L. S., Reynolds, C. F., Alexopoulos, G. S., Bruce, M. L., ... Parmelee, P. (1997). Diagnosis and treatment of depression in late life. Consensus statement update. In Jama The Journal Of The American Medical Association (Vol. 278, pp. 1186-1190).

Lewinsohn, P. M., Seeley, J. R., Roberts, R. E., \& Allen, N. B. (1997). Center for Epidemiologic Studies Depression Scale (CES-D) as a screening instrument for depression among community-residing older adults. Psychology and aging, 12(2), 277-87.

Lucas, R. E., Clark, A. E., Georgellis, Y., \& Diener, E. (2003). Reexamining adaptation and the set point model of happiness: Reactions to changes in marital status. Journal of Personality and Social Psychology, 84(3), 527-539. doi:10.1037/0022-3514.84.3.527

Lucas, R. E., Clark, A. E., Georgellis, Y., \& Diener, E. (2004). Unemployment alters the set point for life satisfaction. Psychological Science, 15(1), 8.

Marmot, M., Banks, J., Blundell, R., Erens, B., Lessof, C., Nazroo, J., \& Huppert, F. A. (2011). English Longitudinal Study of Ageing: Wave 0 (1998,1999 and 2001) and Waves 1-4 (2002-2009).

Colchester, Essex: UK Data Archive. 
Marsh, H. W. (1996). Positive and negative global self-esteem: a substantively meaningful distinction or artifactors? Journal of personality and social psychology, 70(4), 810-9.

McDonald, R. P. (1999). Test Thory: A unified treatment. Mahwah, NJ: Lawrence Erlbaum.

Morrison, M., Tay, L., \& Diener, E. (2011). Subjective well-being and national satisfaction: findings from a worldwide survey. Psychological science, 22(2), 166-71.

doi:10.1177/0956797610396224

Nave, C. S., Sherman, R. A., \& Funder, D. C. (2008). Beyond Self-Report in the Study of Hedonic and Eudaimonic Well-Being: Correlations with Acquaintance Reports, Clinician Judgments and Directly Observed Social Behavior. Journal of research in personality, 42(3), 643-659. doi:10.1016/j.jrp.2007.09.001

Nussbaum, M., \& Sen, A. (1993). The Quality of Life. (M. C. Nussbaum \& A. K. Sen, Eds.)Development (Vol. 1, p. xi, 453). Oxford University Press. doi:10.1093/0198287976.001.0001

Oishi, S. (2006). The concept of life satisfaction across cultures: An IRT analysis. Journal of Research in Personality, 40(4), 411-423. doi:10.1016/j.jrp.2005.02.002

Papassotiropoulos, A., Heun, R., \& Maier, W. (1999). The impact of dementia on the detection of depression in elderly subjects from the general population. Psychological medicine, 29(1), 11320.

Pavot, W., \& Diener, E. (1993). Review of the satisfaction with life scale. Psychological Assessment, $5(2), 164$

Pons, D., Atienza, F. L., Balaguer, I., \& García-Merita, M. L. (2000). Satisfaction with life scale: analysis of factorial invariance for adolescents and elderly persons. Perceptual and motor skills, 91(1), $62-8$.

Radloff, L. S. (1977). The CES-D Scale: A Self-Report Depression Scale for Research in the General Population. Applied psychological measurement, 1(3), 285-401.

Ready, R. E., Vaidya, J. G., Watson, D., Latzman, R. D., Koffel, E. a, \& Clark, L. A. (2011). Age-group differences in facets of positive and negative affect. Aging \& mental health, 15(6), 784-95. doi:10.1080/13607863.2011.562184

Ross, C. E., \& Mirowsky, J. (1984). Components of depressed mood in married men and women. American Journal of epidemiology, 119(6), 997-1004.

Ryan, R. M., \& Deci, E. L. (2000). Self-determination theory and the facilitation of intrinsic motivation, social development, and well-being. The American psychologist, 55(1), 68-78.

Ryan, R. M., \& Deci, E. L. (2001). On happiness and human potentials: A review of research on hedonic and eudaimonic well-being. Annual review of psychology, 52(1), 141-166.

Ryff, C. D., \& Keyes, C. L. M. (1995). The structure of psychological well-being revisited. Journal of personality and social psychology, 69(4), 719.

Ryff, C. D., \& Singer, B. H. (1998). The contours of positive human health. Psychological inquiry, 9(1), $1-28$. 
Seligman, M. E. P., \& Csikszentmihalyi, M. (2000). Positive psychology: An introduction. American psychologist, 55(1), 5.

Shevlin, M., \& Adamson, G. (2005). Alternative factor models and factorial invariance of the GHQ-12: a large sample analysis using confirmatory factor analysis. Psychological assessment, 17(2), 231-6. doi:10.1037/1040-3590.17.2.231

Steptoe, A., \& Wardle, J. (2011). Positive affect measured using ecological momentary assessment and survival in older men and women. Proceedings of the National Academy of Sciences, 108(45), 18244-18248. doi:10.1073/pnas.1110892108

Sumner, L. (1999). Welfare, happiness, and ethics. Oxford: Oxford University Press.

Taylor, S. E., \& Brown, J. D. (1988). Illusion and Well-being: A Social Psychological Perspective on Mental Health. Psychological Bulletin, 103(2), 193-210.

Van de Velde, S., Bracke, P., Levecque, K., \& Meuleman, B. (2010). Gender differences in depression in 25 European countries after eliminating measurement bias in the CES-D 8. Social Science Research, 39(3), 396-404. doi:10.1016/j.ssresearch.2010.01.002

Van den Berg, M. D., Oldehinkel, a J., Bouhuys, a L., Brilman, E. I., Beekman, a T., \& Ormel, J. (2001). Depression in later life: three etiologically different subgroups. Journal of affective disorders, 65(1), 19-26.

Vanhoutte, B. (2012). Measuring subjective well-being in later life: a review. CCSR Working Paper 2012-06. Manchester, UK: CCSR, University of Manchester.

Wallace, R. B., Herzog, A. R., Ofstedal, M. B., Steffick, D., Fonda, S., \& Langa, K. M. (2000). Documentation of Affective Functioning Measures in the Health and Retirement Study. Ann Arbor, MI.

Waterman, A. S. (1993). Two conceptions of happiness: Contrasts of personal expressiveness (eudaimonia) and hedonic enjoyment. Journal of Personality and Social Psychology, 64(4), 678691.

Waterman, A. S. (2007). On the importance of distinguishing hedonia and eudaimonia when contemplating the hedonic treadmill. The American psychologist, 62(6), 612-3. doi:10.1037/0003-066X62.6.612

Watson, D., Clark, L. A., \& Tellegen, A. (1988). Development and validation of brief measures of positive and negative affect: the PANAS scales. Journal of personality and social psychology, 54(6), 1063-70.

Watson, L. C., \& Pignone, M. P. (2003). Screening accuracy for late-life depression in primary care: A systematic review. Journal of Family Practice, 52(12), 956-64.

Wiggins, R. D., Netuveli, G., Hyde, M., Higgs, P., \& Blane, D. (2008). The Evaluation of a Selfenumerated Scale of Quality of Life (CASP-19) in the Context of Research on Ageing: A Combination of Exploratory and Confirmatory Approaches. Social Indicators Research, 89(1), 61-77. doi:10.1007/s11205-007-9220-5 
Wood, A. M., Taylor, P. J., \& Joseph, S. (2010). Does the CES-D measure a continuum from depression to happiness? Comparing substantive and artifactual models. Psychiatry Research, 177(1-2), 120-123. doi:10.1016/j.psychres.2010.02.003

Wu, C., \& Yao, G. (2006). Analysis of factorial invariance across gender in the Taiwan version of the Satisfaction with Life Scale. Personality and Individual Differences, 40(6), 1259-1268. doi:10.1016/j.paid.2005.11.012 


\section{Tables and Figures}

Tables

Table 1: Overview of dimensions of eudaimonic well-being

\begin{tabular}{|c|c|c|}
\hline PWB (Ryff \& Keyes, 1987) & SDT (Ryan \& Deci, 2000) & CASP 19 (Hyde et al. 2003) \\
\hline Autonomy & Autonomy & Autonomy \\
Personal Growth & Competence & \\
Self-acceptance & & \\
Life Purpose & & Control \\
Environmental mastery & & \\
Positive Relatedness & Relatedness & Pleasure \\
& & \\
\hline
\end{tabular}


Table 2: Fit statistics for CFA of 15 item CASP scale in Elsa wave 1

\begin{tabular}{|r|c|c|c|}
\hline & RMSEA & CFI & TLI \\
\hline $\begin{array}{l}\text { One factor } \\
\text { (Quality of life) }\end{array}$ & .097 & .928 & .916 \\
\hline With error correlations & .087 & .942 & .932 \\
\hline $\begin{array}{l}\text { Two factors With error correlations } \\
\text { (Pleasure / Control, Autonomy \& Self-actualisation) }\end{array}$ & .089 & .940 & .929 \\
\hline $\begin{array}{l}\text { Three factors } \\
\text { (Pleasure / Control \& Autonomy / Self-actualisation) }\end{array}$ & .080 & .954 & .945 \\
\hline With error correlations & .072 & .952 & .943 \\
\hline
\end{tabular}


Table 3: Fit statistics for CFA of 8 item CES-D scale in ELSA wave 1

\begin{tabular}{|c|c|c|c|}
\hline & RMSEA & CFI & TLI \\
\hline 1 factor (Depressive Symptoms) & .075 & .964 & .958 \\
\hline With error correlations & .066 & .978 & .958 \\
\hline 2 factors (Somatic / Mood Symptoms) & .054 & .986 & .978 \\
\hline With error correlations & .035 & .994 & .991 \\
\hline
\end{tabular}


Table 4: Fit statistics for CFA of 12 item GHQ scale in ELSA wave 1

\begin{tabular}{|r|c|c|c|}
\hline & RMSEA & CFI & TLI \\
\hline 1 factor (mental health) & .143 & .913 & .894 \\
\hline With error correlations & .072 & .984 & .973 \\
\hline With method factor & .087 & .972 & .961 \\
\hline 2 factors (positive / negative items of mental health ) & .085 & .970 & .963 \\
\hline 3 factors (anxiety / social dysfunction /loss of confidence) & .076 & .977 & .970 \\
\hline
\end{tabular}


Table 5: Fit statistics for CFA of 5 item SWLS scale in ELSA wave 2

\begin{tabular}{|c|c|c|c|}
\hline & RMSEA & CFI & TLI \\
\hline 1 factor (Life satisfaction) & 0.135 & 0.995 & 0.989 \\
\hline 2 factor (Past / Present life satisfaction) & 0.121 & 0.997 & 0.991 \\
\hline With error correlation between a and c & 0.073 & 0.999 & 0.997 \\
\hline
\end{tabular}


Table 6: Overview of scales present in each wave of ELSA

\begin{tabular}{|l|c|c|c|c|c|}
\hline & Wave 1 & Wave 2 & Wave 3 & Wave 4 & Wave 5 \\
\hline CES-D & $\mathrm{X}$ & $\mathrm{X}$ & $\mathrm{X}$ & $\mathrm{X}$ & $\mathrm{X}$ \\
\hline GHQ12 & $\mathrm{X}$ & & $\mathrm{X}$ & & $\mathrm{X}$ \\
\hline SWLS & & $\mathrm{X}$ & $\mathrm{X}$ & $\mathrm{X}$ & $\mathrm{X}$ \\
\hline CASP & $\mathrm{X}$ & $\mathrm{X}$ & $\mathrm{X}$ & $\mathrm{X}$ & $\mathrm{X}$ \\
\hline
\end{tabular}


Table 7: Overview of correlations between sub dimensions in wave 3 of ELSA ( $n=8598)$

\begin{tabular}{|c|c|c|c|c|c|c|c|c|c|}
\hline & $\begin{array}{c}\text { SWLS } \\
\text { Present }\end{array}$ & $\begin{array}{c}\text { SWLS } \\
\text { Past }\end{array}$ & $\begin{array}{l}\text { GHQ } \\
\text { Anxiety }\end{array}$ & $\begin{array}{l}\text { GHQ } \\
\text { Social } \\
\text { dysfuncti } \\
\text { on }\end{array}$ & $\begin{array}{l}\text { GHQ } \\
\text { Loss of } \\
\text { confiden } \\
\text { ce }\end{array}$ & $\begin{array}{c}\text { CES-D } \\
\text { Somatic }\end{array}$ & $\begin{array}{l}\text { CES-D } \\
\text { Mood }\end{array}$ & $\begin{array}{c}\text { CASP } \\
\text { Control \& } \\
\text { Autonomy }\end{array}$ & $\begin{array}{l}\text { CASP } \\
\text { Self- } \\
\text { Realisa } \\
\text { tion }\end{array}$ \\
\hline SWLS Past & 0.926 & & & & & & & & \\
\hline GHQ Anxiety & 0.609 & 0.527 & & & & & & & \\
\hline $\begin{array}{l}\text { GHQ Social } \\
\text { dysfunction }\end{array}$ & 0.579 & 0.454 & 0.715 & & & & & & \\
\hline $\begin{array}{l}\text { GHQ Loss of } \\
\text { confidence }\end{array}$ & 0.593 & 0.521 & 0.857 & 0.748 & & & & & \\
\hline $\begin{array}{l}\text { CES-D } \\
\text { Somatic }\end{array}$ & -0.508 & -0.384 & -0.664 & -0.630 & -0.617 & & & & \\
\hline CES-D Mood & -0.628 & -0.544 & -0.766 & -0.703 & -0.674 & 0.834 & & & \\
\hline $\begin{array}{l}\text { CASP Control } \\
\text { \&Autonomy }\end{array}$ & -0.730 & -0.641 & -0.666 & -0.589 & -0.717 & 0.640 & 0.656 & & \\
\hline $\begin{array}{l}\text { CASP Self- } \\
\text { Realisation }\end{array}$ & 0.779 & 0.753 & 0.546 & 0.617 & 0.607 & -0.667 & -0.639 & -0.847 & \\
\hline CASP Pleasure & 0.710 & 0.732 & 0.582 & 0.566 & 0.648 & -0.512 & -0.646 & -0.790 & 0.886 \\
\hline
\end{tabular}


Table 8: Overview of second order structures

\begin{tabular}{|c|c|c|c|c|c|}
\hline Model 1 & Model 2 & Model 3 & Model 4 & Model 5 & Model 6 \\
\hline GHQ Anxiety & \multirow{10}{*}{$\begin{array}{l}\text { Subjective } \\
\text { Wellbeing }\end{array}$} & \multirow{7}{*}{$\begin{array}{l}\text { Hedonic Well- } \\
\text { being }\end{array}$} & \multirow{5}{*}{$\begin{array}{l}\text { Affective Well- } \\
\text { being }\end{array}$} & \multirow{5}{*}{$\begin{array}{c}\text { Hedonic } \\
\text { Affective } \\
\text { Well-being }\end{array}$} & \multirow{3}{*}{$\mathrm{GHQ}$} \\
\hline $\begin{array}{l}\text { GHQ Social } \\
\text { dysfunction }\end{array}$ & & & & & \\
\hline $\begin{array}{l}\text { GHQ Loss of } \\
\text { confidence }\end{array}$ & & & & & \\
\hline CES-D Somatic & & & & & \multirow{2}{*}{ CES-D } \\
\hline CES-D Mood & & & & & \\
\hline SWLS Present & & & \multirow{5}{*}{$\begin{array}{l}\text { Cognitive Well- } \\
\text { being }\end{array}$} & \multirow{2}{*}{$\begin{array}{c}\text { Hedonic } \\
\text { Cognitive Well- } \\
\text { being }\end{array}$} & \multirow{2}{*}{ SWLS } \\
\hline SWLS Past & & & & & \\
\hline $\begin{array}{l}\text { CASP Control } \\
\text { \&Autonomy }\end{array}$ & & \multirow{3}{*}{$\begin{array}{l}\text { Eudaimonic } \\
\text { Well-being }\end{array}$} & & \multirow{3}{*}{$\begin{array}{l}\text { Eudaimonic } \\
\text { Well-being }\end{array}$} & \multirow{3}{*}{ CASP } \\
\hline $\begin{array}{l}\text { CASP Self- } \\
\text { Realisation }\end{array}$ & & & & & \\
\hline CASP Pleasure & & & & & \\
\hline
\end{tabular}


Table 9: Fit statistics for Second order CFA in wave 3 of ELSA

\begin{tabular}{|l|c|c|c|}
\hline & RMSEA & CFI & TLI \\
\hline Model 1 & 0.052 & 0.954 & 0.948 \\
\hline Model 2 & 0.074 & 0.903 & 0.896 \\
\hline Model 3 & 0.070 & 0.914 & 0.907 \\
\hline Model 4 & 0.058 & 0.940 & 0.935 \\
\hline Model 5 $^{1}$ & 0.053 & 0.950 & 0.946 \\
\hline Model 6 & 0.053 & 0.951 & 0.947 \\
\hline
\end{tabular}

\footnotetext{
${ }^{1}$ One cross loading had to be allowed in this model to avoid a negative covariance of self-realisation with cognitive hedonic well-being. The item "I feel satisfied with the way my life has turned out" of the selfrealisation domain was allowed to load on the hedonic cognitive latent second order factor. This is defendable since the nature of the item explicitly refers to satisfaction with life.
} 
Figures

Figure 1: Schematic representation of measures of hedonic well-being

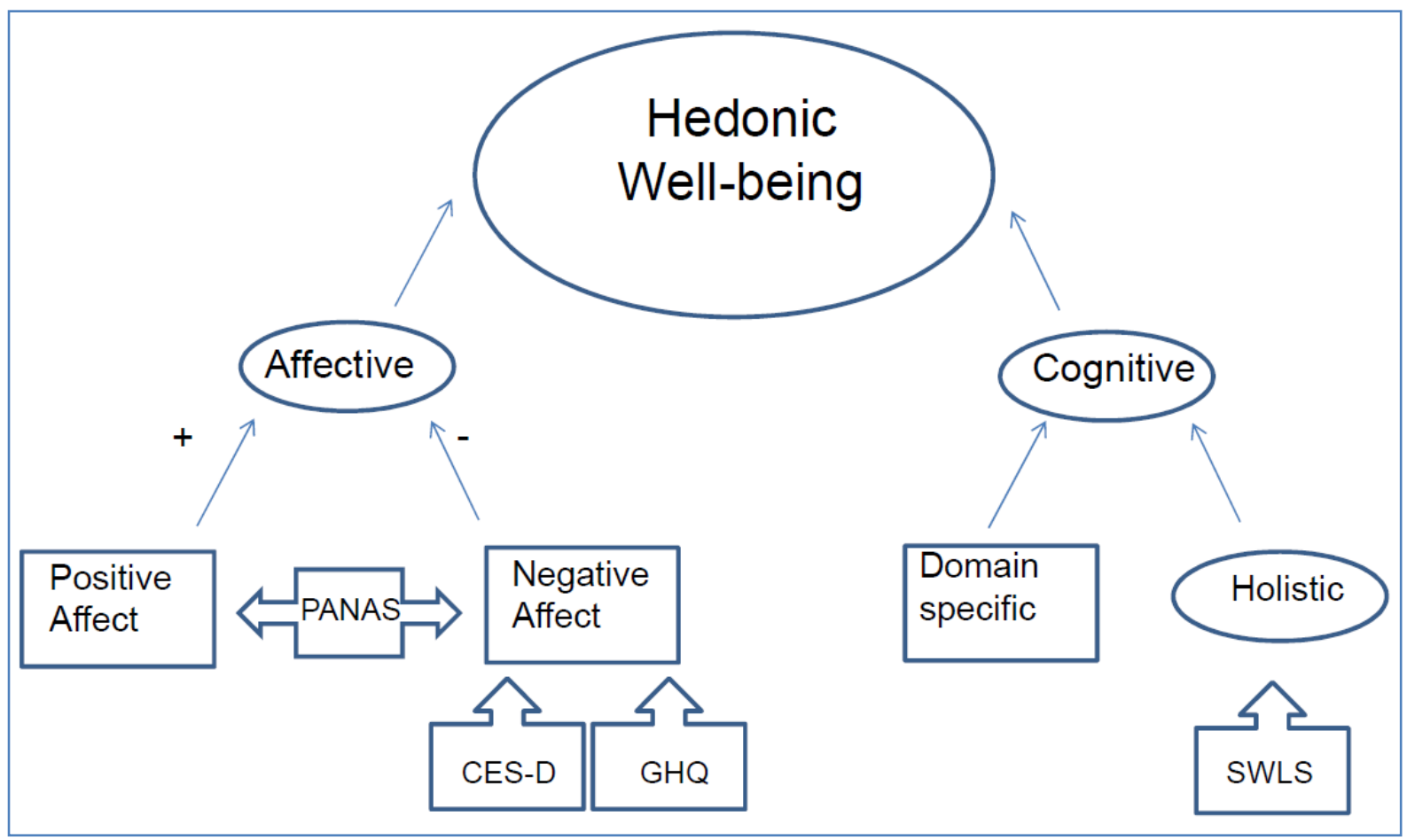


Figure 2: 1 Factor model for CASP 19

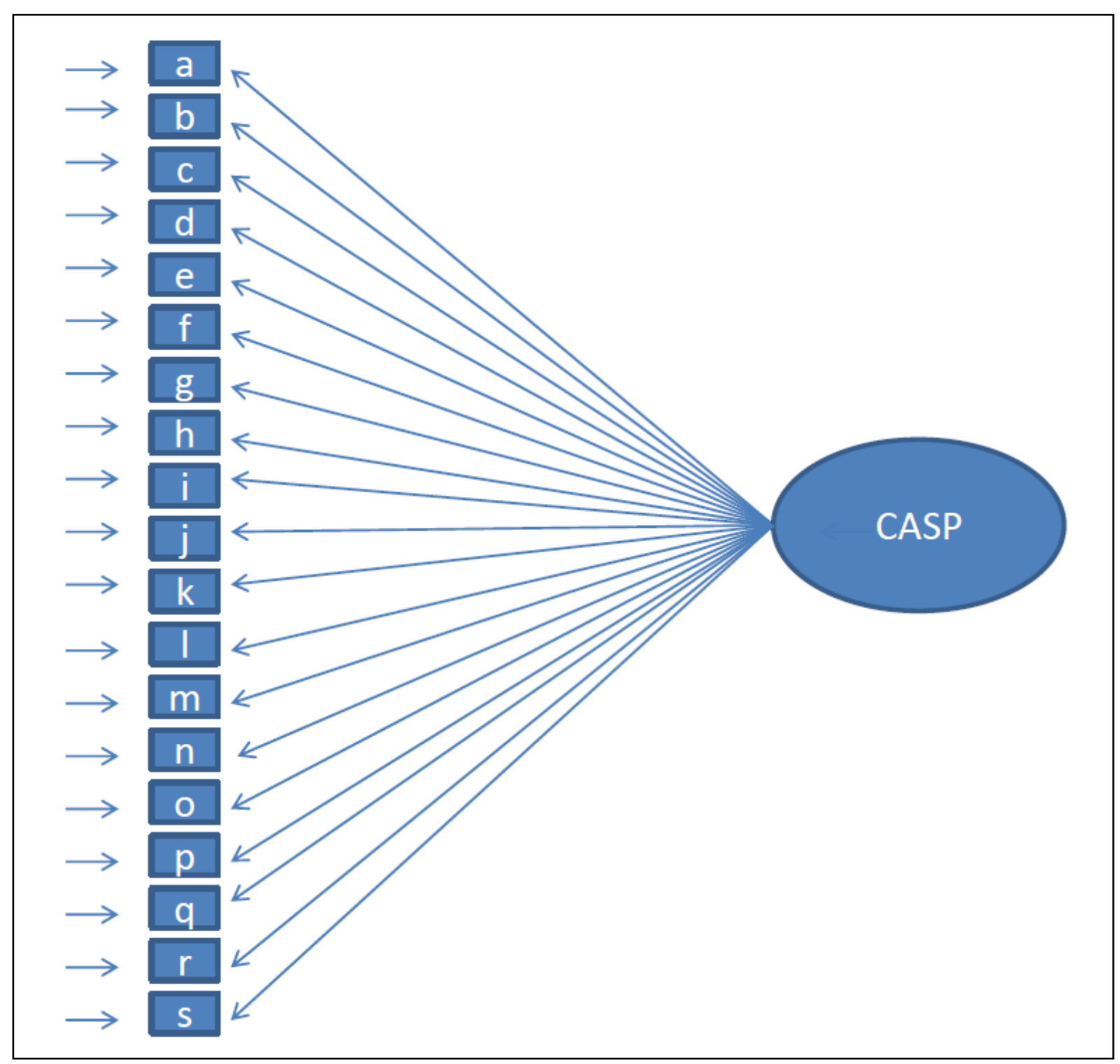


Figure 3: 1 Factor model for CASP 19 with error correlations

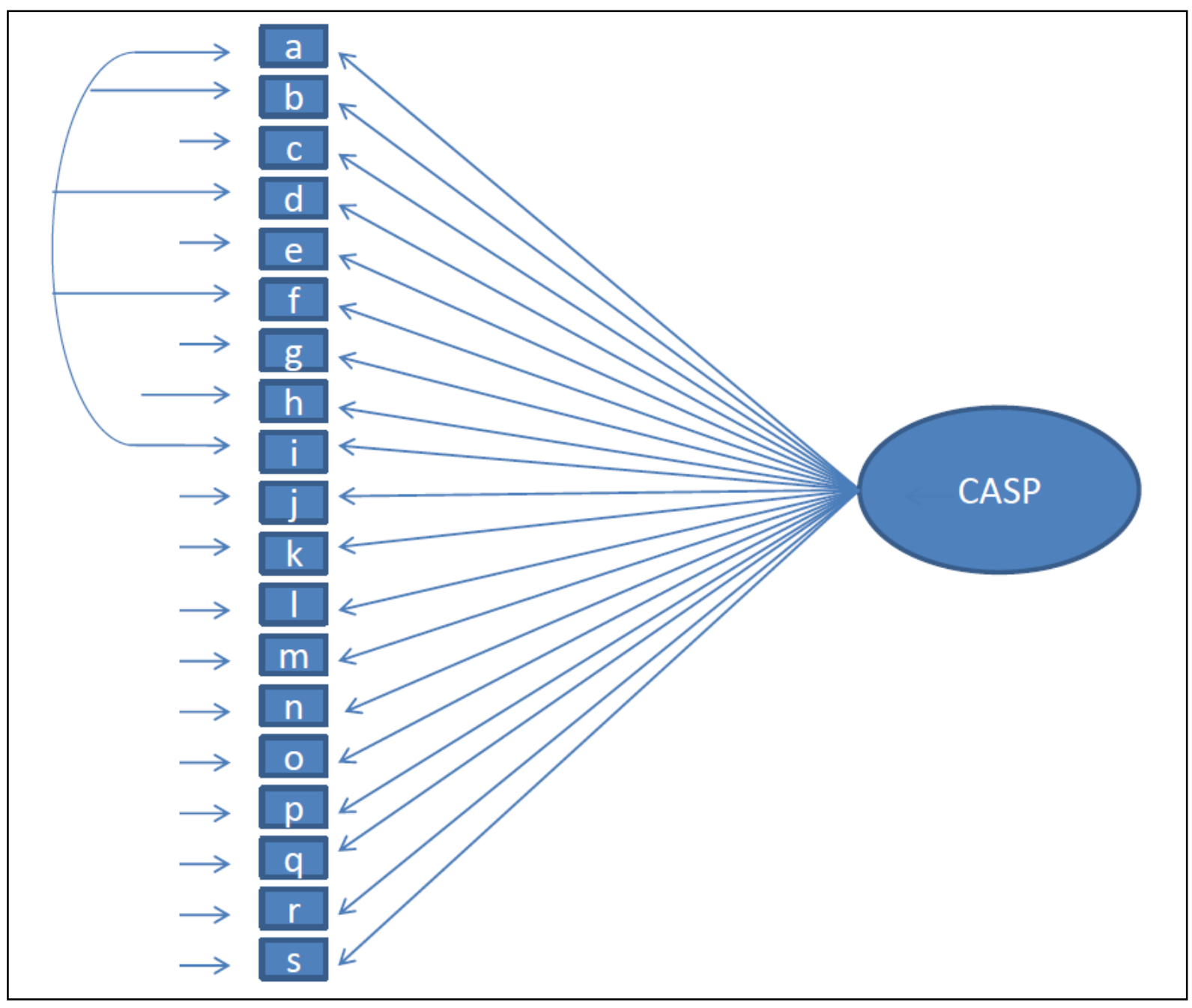


Figure 4: 1 Factor model for CASP 19 with method factor for negatively worded items

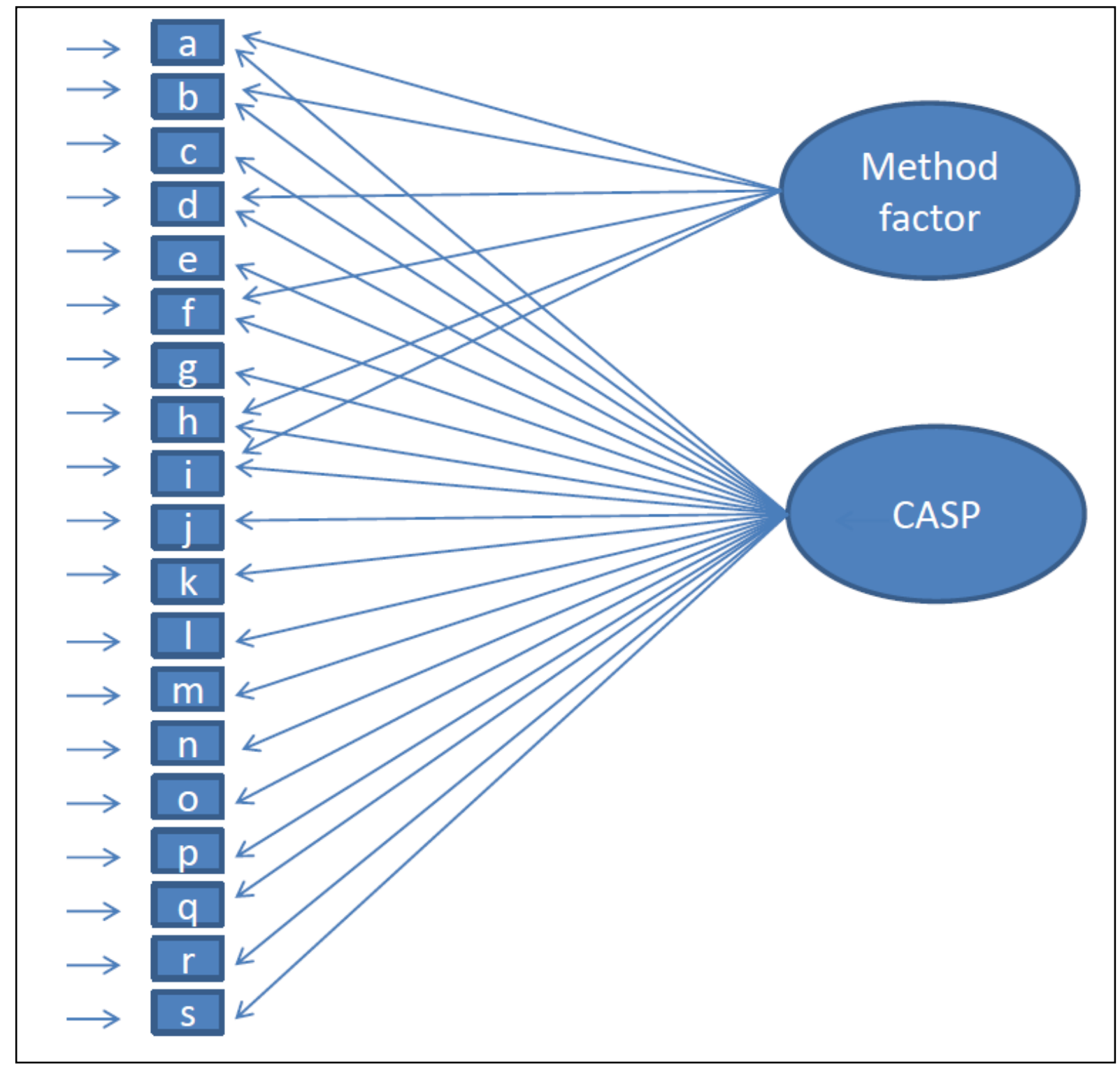


Figure 5: 2 Factor model for CASP 19

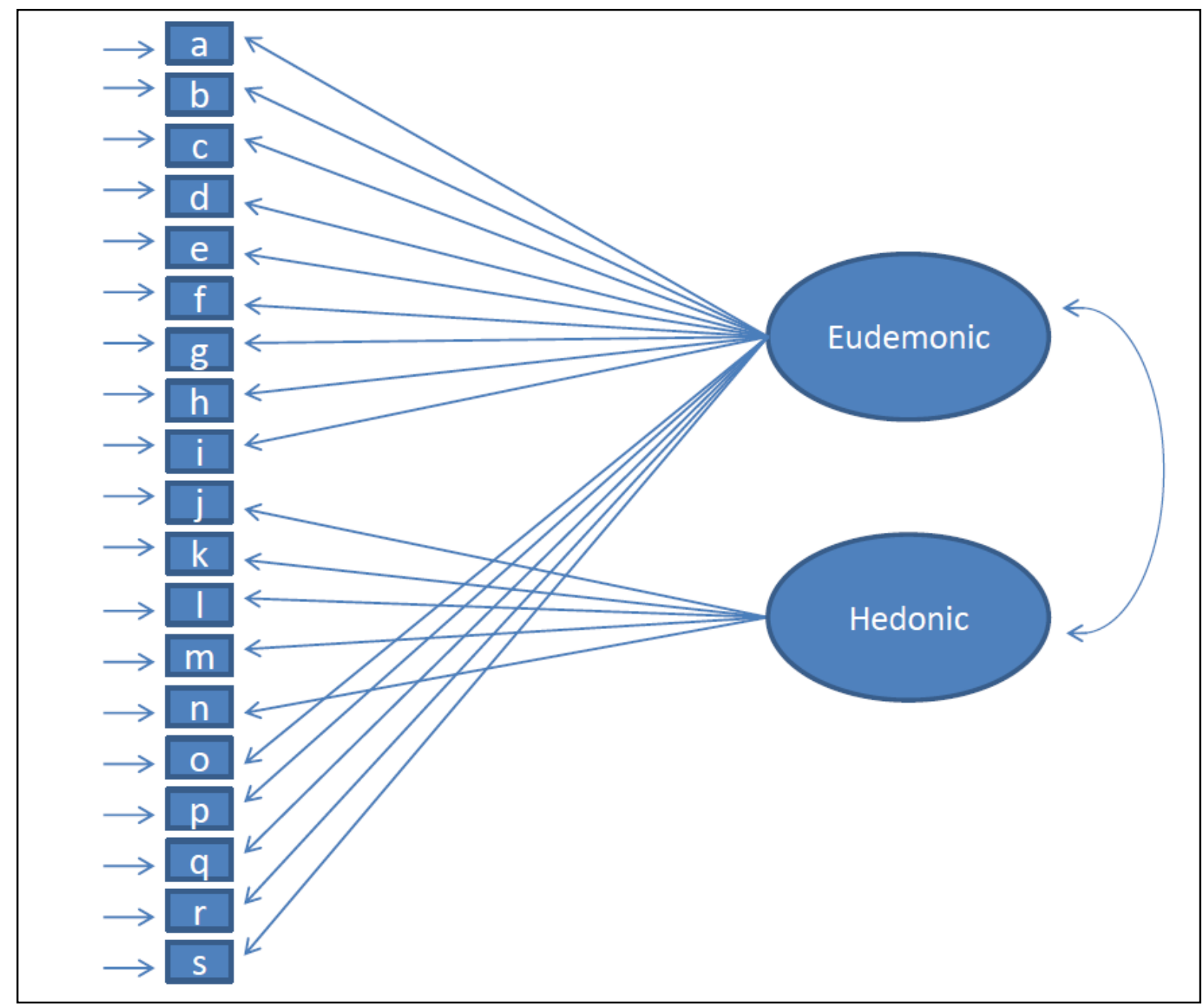


Figure 6: 3 Factor model for CASP 19

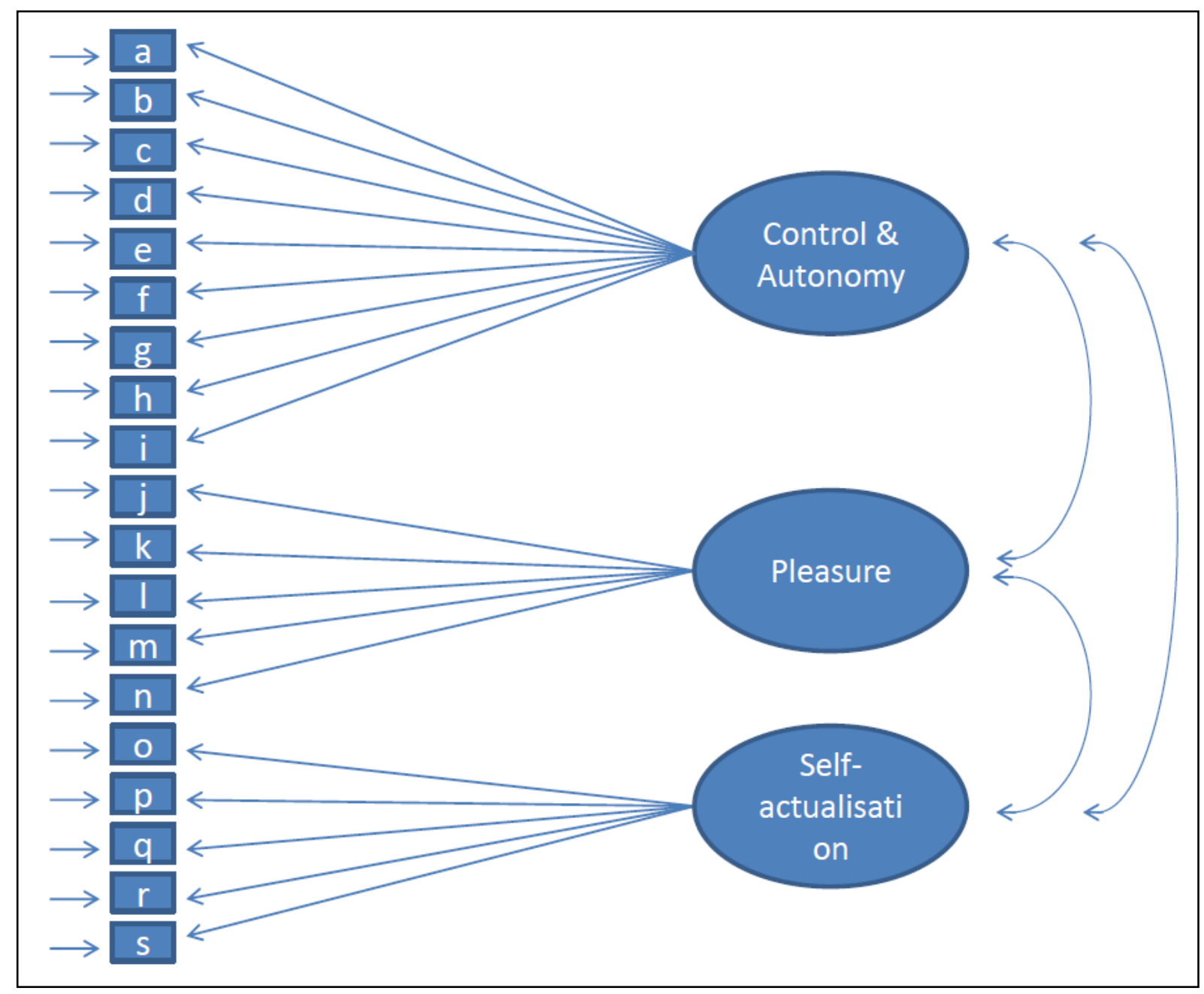




\section{Appendix}

SWLS (Diener, 1984)

a. In most ways my life is close to ideal

b. The conditions of my life are excellent

c. I am satisfied with my life

d. So far, I have gotten the important things I want in life

e. If I could live my life again, I would change almost nothing

Answering categories

1: Strongly agree

2: Agree

3: Slightly agree

4: Neither agree nor disagree

5: Slightly disagree

6: Disagree

7: Strongly disagree

CES-D (Radloff, 1977)

Now think about the past week and the feelings you have experienced. Please tell me if each of the following was true for you much of the time during the past week.

(Much of the time during past week),
a. You felt depressed?
b. You felt that everything you did was an effort?
c. Your sleep was restless
d. You were happy
e. You felt lonely
f. You enjoyed life
g. You felt sad
h. You could no get going

Answering categories

1: Yes

2: No

GHQ (Goldberg, 1988)

We should like to know how your health has been in general over the past few weeks. Have you recently...

a. been able to concentrate on whatever you're doing? 

b. lost much sleep over worry?
c. felt you were playing a useful part in things?
d. felt capable of making decisions?
e. felt constantly under strain?
f. felt you couldn't overcome your difficulties?
g. been able to enjoy your normal day-to-day
activities?
h. been able to face up to your problems?
i. been feeling unhappy and depressed?
j. been losing confidence in yourself?
$k$. been thinking of yourself as a worthless person?
I. been feeling reasonably happy, all things
considered?

\section{Answering categories}

1 Better than usual

2 Same as usual

3 Less than usual

4 Much less than usual

Quality of life (CASP) (Hyde et al., 2003)

Here is a list of statements that people have used to describe their lives or how they feel. We would like to know how often, if at all, you think they apply to you.

\section{Control}

a. My age prevents me from doing the things I would like to.

b. I feel that what happens to me is out of control.

c. I feel free to plan things for the future.

d. I feel left out of things.

\section{Autonomy}

e. I can do the things that I want to do.

f. Family responsibilities prevent me from doing what I want to do.

g. I feel that I can please myself what I can do.

h. My health stops me from doing the things I want to do.

i. Shortage of money stops me from doing the things I want to do.

\section{Pleasure}

j. I look forward to each day.

k. I feel that my life has meaning.

I. I enjoy the things that I do.

$\mathrm{m}$. I enjoy being in the company of others.

n. On balance, I look back on my life with a sense of happiness.

\section{Self-realization}


o. I feel full of energy these days.

p. I choose to do things that I have never done before.

q. I feel satisfied with the way my life has turned out.

r. I feel that life is full of opportunities.

s. I feel that the future looks good for me.

\section{Answering categories}

\section{Often}

2 Sometimes

3 Not often

4 Never

\footnotetext{
i The data were made available through the UK Data Archive (UKDA). ELSA was developed by a team of researchers based at the National Centre for Social Research, University College London and the Institute for Fiscal Studies. The data were collected by the National Centre for Social Research. The funding is provided by the National Institute of Aging in the United States, and a consortium of UK government departments coordinated by the Office for National Statistics. The developers and funders of ELSA and the Archive do not bear any responsibility for the analyses or interpretations presented here.

ii Preliminary analysis on waves 1 and 2 point to similar results.

iii Positive affect apparently is available for a subsample of ELSA respondents, who provided saliva samples, through ecological momentary assessments derived from their logbooks (Steptoe \& Wardle, 2011). These data are not part of the current version of the ELSA dataset.

${ }^{i v}$ An alternative model with pleasure as a part of hedonic wellbeing did not converge, indicating a worse model specification.
} 